\section{A dramaturgia dos peritos na ciência regulatória brasileira: o caso da Comissão Técnica Nacional de Biossegurança}

\section{The dramaturgy of experts in Brazilian regulatory science: the case of the National Technical Commission for Biosecurity}

\section{Paulo F.C. Fonseca}

Professor, Centro de Cultura, Linguagem e Tecnologias Aplicadas/ Universidade Federal do Recôncavo da Bahia.

Santo Amaro - BA - Brasil

orcid.org/0000-0003-3403-0753

dopaulo@gmail.com

\section{Julia S. Guivant}

Professora, Departamento de Sociologia e Ciência Política/ Universidade Federal de Santa Catarina.

Florianópolis - SC - Brasil

orcid.org/0000-0001-6201-887X

juliaguivant@gmail.com

Recebido em 19 abr. 2017.

Aprovado em 16 abr. 2018
FONSECA, Paulo F.C.; GUIVANT, Julia S. A dramaturgia dos peritos na ciência regulatória brasileira: o caso da Comissão Técnica Nacional de Biossegurança. História, Ciências, Saúde - Manguinhos, Rio de Janeiro, v.26, n.1, jan.-mar. 2019, p.123-144.

Resumo

A partir de estudo sobre a Comissão Técnica Nacional de Biotecnologia, órgão que concentra as competências de regulação de organismos geneticamente modificados no Brasil, o artigo apresenta uma análise, fundamentada na abordagem interacionista de Goffman, sobre sua atuação. Analisa a comissão como um teatro onde diferentes peritos realizam performances, atuam num palco, com uma plateia, bastidores e conflitos em relação aos papéis representados. Por meio de tais estratégias é possível entender o processo de consolidação e estabilização da comissão como instância decisória sobre organismos geneticamente modificados no Brasil. A estabilização da comissão está associada a uma gestão de palco que remove os conflitos para os bastidores e apresenta as decisões como isentas de interferências políticas ou interesses pessoais.

Palavras-chave: ciência regulatória; dramaturgia; CTNBio; OGM; Brasil.

\section{Abstract}

This article investigates the Brazilian National Technical Commission on Biosecurity, an agency empowered to regulate genetically modified organisms in the country, and presents an analysis of its performance based on Goffman's interactionist approach. The commission is analyzed as if it were a theater in which different experts perform and act on stage, with an audience, a backstage area, and conflicts related to the roles represented. These strategies make it possible to understand the process of consolidating and stabilizing this commission as a decisionmaking body on genetically modified organisms in Brazil. The stabilization of the commission is associated with stage management that takes conflicts out of the public view and moves them behind the scenes, presenting decisions as free from political interference or personal interests.

Keywords: regulatory science; dramaturgy; CTNBio; GMOs; Brazil. 
C iência regulatória é uma denominação dada à ciência que informa diretamente a regulação de inovações científicas e tecnológicas (Jasanoff, 1990, 1995). Neste artigo, propomos analisar o papel da ciência regulatória nas atividades da Comissão Técnica Nacional de Biossegurança (CTNBio), órgão responsável pela deliberação e regulamentação da introdução e fiscalização de inovações a partir de critérios técnico-científicos de avaliação e gestão de riscos dos organismos geneticamente modificados (OGMs). O modelo regulatório brasileiro definido pela nova lei de biossegurança (Brasil, 24 mar. 2005), ao contrário do que acontece, por exemplo, no âmbito norte-americano (NAS, 2016), concentra toda e qualquer deliberação sobre assuntos relacionados a OGMs numa única comissão técnica.

O processo de transgenização da produção agrícola brasileira ocorreu em meio a disputas de natureza política, econômica, social, institucional e científica; dimensões que se apresentam de forma imbricada e indissociável. Entretanto, a partir da aprovação da nova Lei de Biossegurança, em 2005, a coalizão de atores heterogêneos que historicamente se posicionaram de forma contrária ao processo de transgenização da agricultura (Guivant, 2002, 2009; Guivant, Macnagthen, 2015) foi perdendo força política, enquanto cresceu a área de produção transgênica e a aprovação comercial de novas variedades de OGMs. Com a acelerada adoção dessas variedades por parte dos produtores rurais - o Brasil é hoje o segundo maior produtor de transgênicos do mundo (James, 2015) - e certa indiferença do público frente à temática, consideramos que um espaço privilegiado para entender sua dinâmica é o da ciência regulatória realizada na CTNBio.

A abordagem teórica que norteia nossa análise se fundamenta na metáfora da performance teatral de Erving Goffman (2004), tal como foi elaborada por Stephen Hilgartner (2000) especificamente para o caso de instituições de aconselhamento científico. Essa perspectiva nos permitirá entender os mecanismos pelos quais a CTNBio constrói a legitimidade de suas decisões e como administra as possíveis divergências. Consideramos que os peritos nos comitês de regulação têm um papel fundamental, o de "purificar" esses temas incertos de "contaminações" políticas e, assim, evitar tendências desestabilizadoras ou questionamentos públicos (Hilgartner, 2000, p.4). A consideração da produção de conhecimento nesta esfera como uma performance teatral é uma forma eficaz de se "abrir a caixa preta" de suas instituições (Latour, 1987) e iluminar sociologicamente a forma como elas constroem sua legitimidade.

A metodologia se fundamenta na perspectiva da etnografia multissituada (Marcus, 1995), que orienta para uma aproximação não apenas com os atores humanos situados em um determinado espaço-tempo, mas com o conjunto de elementos heterogêneos que compõem a rede sociotécnica da CTNBio. Conforme argumentamos a seguir, assim como Hilgartner (2000), dirigimos o foco da investigação para as performances da CTNBio, que se dão sobretudo por meio da construção de inscrições, ou seja, documentos que oficialmente registram não apenas as deliberações, mas o funcionamento e as características da comissão. O trabalho de campo se dirigiu, assim, à circulação, difusa no espaço-tempo, dos objetos, significados e identidades culturais associados à CTNBio (Marcus, 1995, p.96).

A pesquisa etnográfica se deu, especialmente, a partir de fontes documentais, cobrindo o período de janeiro de 2005 (três meses antes da aprovação da nova Lei de Biossegurança) até dezembro de 2016. Como fontes primárias foram consideradas toda a documentação 
produzida pela CTNBio (pareceres técnicos, atas e pautas de reunião, regimento interno, resoluções normativas, registros de audiências públicas, pareceres de consultoria jurídica, comunicados e, de forma não exaustiva, cópias de processos internos de pedidos de liberação comercial) e toda a legislação a ela referente. Como fontes secundárias foram utilizadas publicações diversas, como: reportagens, artigos e entrevistas na imprensa; debates acadêmicos (presentes em publicações das sociedades científicas), livros e sites publicados por organizações governamentais e da sociedade civil; e publicações em periódicos científicos, oriundas das ciências naturais e das ciências sociais.

Foi realizada observação participante em duas sessões de reuniões deliberativas, ocorridas em abril e novembro de 2016 (conforme se coloca a seguir, o difícil acesso às reuniões acabou por se tornar um importante dado analítico). Foram também realizadas entrevistas com atores envolvidos diretamente com a CTNBio (um membro, um ex-membro e dois servidores da secretaria executiva da comissão, cujos anonimatos foram assegurados), feitas entre abril de 2016 e fevereiro de 2017. Esse conjunto heterogêneo de dados foi organizado e categorizado com o auxílio de um software para a análise qualitativa de dados.

$\mathrm{Na}$ primeira parte deste artigo, apresentamos nosso referencial teórico. A seguir, caracterizamos a CTNBio, para posteriormente estudar o seu script performático (pareceres, audiências e conflitos internos). Para concluir, consideramos como a análise pode contribuir para a compreensão sobre especificidades da ciência regulatória brasileira.

\section{A performance dos peritos e os modelos de ciência}

A abordagem dramatúrgica de Goffman aponta que as interações cotidianas podem ser interpretadas como representações de papéis, ou pela projeção intencional dos indivíduos sobre suas personalidades e sobre significados de suas ações. Mais que uma simples metáfora, em sua obra $A$ representação do eu na vida cotidiana, Goffman (2004) apresenta o teatro como uma forma de se compreender como as pessoas ativamente selecionam informações e técnicas comunicativas para assegurar que o interlocutor assimile determinada imagem de si próprio. Da mesma maneira, para conseguir convencer os públicos interessados, os responsáveis pelo aconselhamento científico para decisões regulatórias ativamente constroem sua imagem de competência e confiabilidade. Eles se comportam de forma a demonstrar integridade e objetividade.

A associação da ciência regulatória a uma dramaturgia, como sugere Hilgartner (2000, 2004), ocorre de maneira bastante imediata, a partir dos seguintes aspectos: (1) os relatórios e recomendações são performances; (2) os peritos são atores que performam seu trabalho diante de uma audiência, valendo-se de técnicas de representação para colocar em prática a base de sua autoridade enquanto peritos; (3) os críticos são também performadores que usam a técnica teatral para desafiar os pareceres; (4) os debates acerca dos relatórios são disputas teatrais; e (5) há a atuação de uma equipe de apoio, que fica nos bastidores e não deve aparecer. A qualidade da gestão do palco e dos bastidores, ou seja, a escolha adequada sobre que informação deve ser tornada pública, é decisiva para que a representação seja mais ou menos convincente, ou para que a deliberação reguladora tenha maior ou menor legitimação (Hilgartner, 2000, p.6). A partir dessa metáfora do teatro é possível enxergar 
melhor o trabalho de purificação, isto é, o esforço por apagar marcas de preferência política, interesses ou conflitos nos documentos oficiais, quando os atores vão dos bastidores para o palco, e vice-versa. A distinção entre palco e bastidores aponta para uma importante relação entre presenças e ausências. Enquanto as discordâncias e interesses estão presentes nos bastidores, há um esforço por parte da CTNBio para que elas estejam ausentes dos documentos finais, por exemplo, quando criam pareceres que disfarçam essas marcas de conflitos e interesses.

A partir desse enquadramento teórico, procura-se entender como os atores se apresentam com a intenção de passar uma imagem convincente para a audiência. Em lugar de partir da credibilidade ou legitimidade desse espaço como algo dado, esse tipo de enfoque nos permitirá entender como se constitui a autoridade dos peritos (Hilgartner, 2000, p.7).

Ainda que desenvolvidos a partir de outros interesses e propósitos, os fundamentos interacionistas são particularmente congruentes com muitas das abordagens desenvolvidas pelos estudos sociais da ciência e tecnologia (ESCT), e não por acaso o intercâmbio entre essas duas correntes de pensamento tem se consolidado de forma robusta (Law, 2008). Os ESCT têm mostrado que as fronteiras entre o domínio natural e o cultural não são coerentemente identificáveis, quer em seus aspectos estruturais, quer em suas dinâmicas de produção e transformação (Latour, 1987; Winner, 1983). No entanto, uma das premissas comuns para a governança dos riscos relacionados com tecnologias emergentes tem sido justamente a busca pela separação entre o social e o técnico, entre o científico e o moral. É nesse pressuposto também que se insere a imagem usualmente atribuída à ciência regulatória como sendo uma zona de demarcação de fronteiras entre juízos de valor e fatos. Segundo essa perspectiva, a análise dos riscos de novas tecnologias deveria ser delegada aos peritos, com sólida formação científica na área enfocada, que devem atuar conforme os valores de uma ciência universal e desinteressada (Beck, 1992). Os peritos deveriam ser os responsáveis por produzir o conhecimento básico e politicamente isento para que, a partir deles, sejam tomadas as decisões políticas.

No entanto, conforme aponta Jasanoff $(1990,1995)$, entre outros, essa suposta separação entre fatos e valores não é adequada para caracterizar os saberes e práticas científicas que informam os tomadores de decisão sobre regulações. Segundo a autora, enquanto a "ciência de pesquisa" tende a ser conduzida em ambientes relativamente consensuais, isto é, quando e onde protocolos metodológicos e padrões de qualidade são relativamente estáveis, a ciência regulatória costuma ocorrer em contextos em que os critérios e padrões de análise "tendem a ser mais fluidos, controversos e sujeitos a considerações políticas" (Jasanoff, 1995, p.282). ${ }^{1}$

No processo de "purificação" das decisões de influências políticas, os peritos tendem a se valer do modelo standard de ciência, que consideraria que as diferenças de apreciação dos riscos entre peritos e leigos devem-se, entre muito, a atitudes irracionais destes últimos, atribuídas a um deficit de conhecimento que os leva a vieses cognitivos (Joly, 2001; Guivant, 2005 , 2007). A paritr dessa perspectiva, haveria uma separação clara entre fatos e valores. A ciência corresponderia a uma prática independente de influências políticas, econômicas ou sociais. A comunicação dos riscos se realiza numa direção linear, de acordo com o que se 
denomina modelo do deficit: os peritos - objetivos e neutros - comunicam os conhecimentos aos leigos para evitar que permaneçam na ignorância e irracionalidade (Jasanoff, 2005).

Os questionamentos sobre a legitimidade do aconselhamento científico se dão de forma situada e dependem crucialmente de circunstâncias e universos culturais específicos. Nos EUA, marcados por uma tradição de regulação adversarial (Jasanoff, 2005), é hoje um clichê a percepção de que cientistas podem ser "armas contratadas" e que para cada perito favorável pode ser encontrado um perito contrário (Hilgartner, 2000). Da mesma forma, o rechaço de grande parte dos países europeus à liberação do plantio de plantas geneticamente modificadas, contrariando as recomendações da European Food Safety Authority (EFSA), a instituição reguladora da Comissão Europeia, indica que há grave erosão na legitimidade dos regimes de regulação supranacionais (Wickson, Wynne). No Brasil, temos fortes indícios de que, ao contrário do que acontece em ambos os lados do Atlântico Norte, há uma cultura política de menor intensidade crítica a uma concepção mais positivista de ciência e tecnologia (CGEE, 2015; Macnaghten, Guivant, 2011; Guivant, 2006).

Para caracterizar a construção da legitimidade da ciência regulatória brasileira, analisaremos como se dão as performances no âmbito da CTNBio. Por meio da análise da representação dos papéis envolvidos nas dinâmicas de deliberação e regulação na CTNBio, buscaremos evidenciar possíveis características que estejam relacionadas com a estabilização de sua legitimidade para adotar uma práxis deliberativa que tem traduzido os interesses da coalizão favorável aos transgênicos.

\section{A Comissão Técnica Nacional de Biossegurança (CTNBio)}

Com a aprovação da chamada nova Lei de Biossegurança, lei n.11.105/2005 (Brasil, 24 mar. 2005), em substituição à lei n.8.974/95 (Brasil, 5 jan. 1995), a CTNBio foi significativamente reconfigurada. Na nova lei, a comissão é definida como uma "instância colegiada multidisciplinar de caráter consultivo e deliberativo, integrante do Ministério da Ciência e Tecnologia", cujo mandato é

prestar apoio técnico e de assessoramento ao Governo Federal na formulação, atualização e implementação da Política Nacional de Biossegurança de OGM e seus derivados, bem como no estabelecimento de normas técnicas de segurança e de pareceres técnicos referentes à autorização para atividades que envolvam pesquisa e uso comercial de OGM e seus derivados, com base na avaliação de seu risco zoofitossanitário, à saúde humana e ao meio ambiente (Brasil, 24 mar. 2005, art. 10).

A comissão passou a ser formada por 27 membros titulares e 27 suplentes, com "grau acadêmico de doutor e com destacada atividade profissional nas áreas de biossegurança, biotecnologia, biologia, saúde humana e animal ou meio ambiente" (Brasil, 24 mar. 2005, art. 11). A Tabela 1 apresenta a composição da nova CTNBio. 
Tabela 1: Composição da CTNBio

\begin{tabular}{|c|c|c|c|}
\hline Critérios de escolha & Área de especialização/representação & $\begin{array}{l}\text { Número de } \\
\text { membros }\end{array}$ & Total \\
\hline \multirow{4}{*}{$\begin{array}{l}\text { Listas tríplices da } \\
\text { comunidade científica, } \\
\text { definição do MCTIC }\end{array}$} & Saúde & 3 & \multirow{4}{*}{12} \\
\hline & Animal & 3 & \\
\hline & Vegetal & 3 & \\
\hline & Meio ambiente & 3 & \\
\hline \multirow{9}{*}{$\begin{array}{l}\text { Definição direta dos } \\
\text { ministérios }\end{array}$} & $\begin{array}{l}\text { Ministério da Ciência, Tecnologia, Inovações e } \\
\text { Comunicações (MCTIC) }\end{array}$ & 1 & \multirow{9}{*}{9} \\
\hline & Ministério da Agricultura, Pecuária e Abastecimento (Mapa) & 1 & \\
\hline & Ministério da Saúde (MS) & 1 & \\
\hline & Ministério do Meio Ambiente (MMA) & 1 & \\
\hline & Ministério do Desenvolvimento Agrário (MDA) & 1 & \\
\hline & Ministério da Indústria e Comércio Exterior (MDIC) & 1 & \\
\hline & Ministério da Defesa (MD) & 1 & \\
\hline & Secretaria da Aquicultura e Pesca (SAP) & 1 & \\
\hline & Ministério das Relações Exteriores (MRE) & 1 & \\
\hline \multirow{6}{*}{$\begin{array}{l}\text { Listas tríplices de } \\
\text { entidades da sociedade } \\
\text { civil, definição dos } \\
\text { ministérios associados } \\
\text { à área }\end{array}$} & Defesa do consumidor (Ministério da Justiça) & 1 & \multirow{6}{*}{6} \\
\hline & Saúde (MS) & 1 & \\
\hline & Meio ambiente (MMA) & 1 & \\
\hline & Biotecnologia (MCTIC) & 1 & \\
\hline & Agricultura familiar (MDA) & 1 & \\
\hline & Saúde do trabalhador (Ministério do Trabalho) & 1 & \\
\hline
\end{tabular}

Fonte: elaborada pelos autores, a partir da lei n.11.105/2005.

São 12 representantes titulares (com seus respectivos 12 suplentes) da comunidade científica, nove representantes titulares (e nove suplentes) do Poder Executivo e seis representantes titulares (e seis suplentes) da sociedade civil, sendo que todos eles devem ser nomeados em listas tríplices por suas credenciais científicas, mas definidos por ministérios do Poder Executivo.

Além dos 54 integrantes, incluindo suplentes e titulares, a CTNBio é constituída por 23 funcionários da Secretaria Executiva (Secretaria..., s.d.). Esse grupo de servidores do Ministério da Ciência, Tecnologia, Inovações e Comunicações (MCTIC) com dedicação exclusiva à CTNBio é responsável por toda a gestão operacional do órgão, com atribuições diversas, como tramitação dos processos, o apoio técnico e administrativo de seus membros e a publicitação das informações relativas à CTNBio. Conforme pretende-se deixar claro neste artigo, a Secretaria Executiva, muitas vezes negligenciada nas análises sobre a CTNBio, tem uma atuação decisiva para a gestão de palco, particularmente no controle de informações que devem ser visibilizadas ou ocultadas para as audiências, além do próprio controle da presença de espectadores externos nas reuniões do colegiado.

O ministro de Ciência e Tecnologia deve definir um presidente, a partir de lista tríplice votada no plenário. O mandato do presidente é de dois anos, renováveis por igual período. 
Os membros, que também têm mandato de dois anos, mas podem renovar por outros dois períodos, não são remunerados pelas atividades. Evidentemente, o presidente é um personagem relevante, que tem poderes e obrigações distintas das dos demais integrantes. É ele (ou ela, ainda que até hoje apenas homens a tenham presidido) o diretor da peça, o responsável não apenas por encadear as diversas performances, na medida em que concentra competências processuais e deliberativas, mas que também tem a responsabilidade de "representar a CTNBio" (art. 12, I, regimento interno da CTNBio).

A CTNBio tem quatro subcomissões setoriais permanentes, cada uma relacionada com uma das áreas de especialidade apresentadas na lei n.11.105/2005: as áreas de saúde humana, animal, vegetal e ambiental. Cada subcomissão deve ser composta de ao menos cinco membros com reconhecida perícia na área, entre titulares e suplentes. O regimento também prediz a possibilidade de criação de subcomissões extraordinárias, mas na prática, até o momento, a CTNBio apresenta apenas as quatro subcomissões, que atuam de forma agregada, em pares, tratando simultaneamente de duas das áreas: a subcomissão vegetal/ ambiental e a subcomissão animal/humana.

Os integrantes da CTNBio se reúnem mensalmente, em Brasília, por dois dias. No primeiro dia, realizam-se atividades nas duas subcomissões setoriais (a subcomissão vegetal/ambiental se reúne durante todo o dia, e a subcomissão animal/humana, apenas na parte da tarde) e, no dia seguinte, ocorre a plenária com todos os integrantes para discussão e votação sobre eventuais deliberações. As regras relativas a cada tipo de avaliação efetuada pela CTNBio estão presentes nas Resoluções Normativas, que foram elaboradas pelo próprio órgão após a aprovação da lei em 2005. Ou seja, a CTNBio tem o poder não apenas de decidir a partir de regras preestabelecidas acerca dos critérios de análise de risco, mas também de decidir quais as regras a serem adotadas. Não por acaso, as resoluções normativas são recorrentemente um objeto de disputa. Por exemplo, ilustrando também o papel relevante da presidência da CTNBio, em 2009, então em seu quarto ano de mandato como presidente, Walter Colli empenhou-se publicamente em alterar a Resolução Normativa n.5, que dispunha sobre as regras de monitoramento pós-liberação comercial (Lixo..., 10 dez. 2009), o que foi de fato realizado.

Desse modo, a CTNBio é uma comissão legalmente desenhada para oferecer, como o próprio nome diz, uma análise técnica e procedimental a respeito de questões relacionadas à biossegurança dos OGMs no país. Trata-se de uma aposta cristalina no modelo standard de ciência, na medida em que se pressupõe que o colegiado de cientistas tenha autonomia e competência para definir, caso a caso, todas as questões relativas aos OGMs no país.

Segundo a lei n.11.105/2005, as decisões tomadas pela plenária da CTNBio só respondem ao Conselho Nacional de Biossegurança (CNBS), um colegiado formado pelos mesmos ministérios representados na CTNBio, que se constitui como autoridade máxima na política nacional de biossegurança e que deve se reunir quando convocado pelo ministro de Estado chefe da Casa Civil ou mediante provocação da maioria de seus membros. É interessante notar que a própria legislação brasileira reconhece que, em última instância, o processo de deliberação regulatória sobre os OGMs é político. No entanto, desde sua criação, o CNBS se reuniu apenas três vezes. A última reunião do CNBS se deu no dia 31 de julho de 2008, quando foi publicada a sua última resolução normativa, que ratificou a decisão da 
CTNBio relativa à aprovação para comercialização do milho BT11, da empresa Syngenta. Assim, o CNBS tem exercido sobretudo um papel de "não atuação" e, consequentemente, de corroboração de que o que deve guiar as decisões é a análise técnica da CTNBio.

Conforme iremos discutir a seguir, a posição da CTNBio como instância máxima de deliberação acerca dos transgênicos tem sido sustentada a partir de seus ritos processuais, que buscam produzir uma imagem de um colegiado de cientistas competentes e isentos.

\section{O script performático da Comissão Técnica Nacional de Biossegurança}

Segundo o regimento interno da CTNBio (Brasil, 6 mar. 2006), para cada pleito submetido à CTNBio, a Secretaria Executiva deve encaminhar o processo para a análise de uma ou mais das subcomissões que, por meio de seu coordenador, deve indicar um dos membros, seja titular ou suplente, para a relatoria e elaboração de parecer conclusivo sobre o requerimento da entidade proponente. Segundo integrantes da secretaria entrevistados, essa escolha é feita a partir de critérios de distribuição isonômica de trabalhos e de adequação às áreas de atuação e competência dos membros pareceristas. O parecer final, após sua aprovação nas Subcomissões Setoriais ou Extraordinárias para as quais o processo foi distribuído, é encaminhado ao plenário da CTNBio para deliberação.

Os relatores de um determinado processo ficam encarregados de elaborar a fundamentação para se chegar a um parecer técnico, final e conclusivo sobre uma determinada demanda solicitada à CTNBio, como o licenciamento ou a renovação da licença de instituições credenciadas para atuar com OGMs, pedidos de liberação planejada (plantio de forma experimental), pedidos de importação e exportação de OGMs ou derivados e, de forma mais crítica, pedidos de liberação comercial. Os pareceres devem ser elaborados a partir da análise das informações submetidas pela solicitante (obedecendo às exigências contidas nas resoluções normativas que versam sobre quais as informações necessárias para cada tipo de demanda) e por outras fontes da literatura científica, além de, quando necessário, a solicitação a pareceristas externos ad hoc.

Não há uma forma rígida para a estrutura e conteúdo do parecer, mas é possível encontrar um padrão dentre os pareceres já emitidos. Além de apresentar as informações gerais do pedido submetido à CTNBio (designação, requerente, espécie, característica inserida pela transgenia, método utilizado, uso proposto), o documento apresenta-se como um estudo científico sobre a sua biossegurança, perpassando as características do OGM e de seus métodos de obtenção até chegar a uma análise conclusiva específica acerca dos riscos para a saúde e para o meio ambiente que fundamente a deliberação na plenária. Tende-se a recorrer ao chamado princípio de equivalência substancial, que consiste na comparação de características agronômicas, nutricionais e de toxicidade com a espécie original, indicando se foram verificadas divergências com os parâmetros conhecidos (NAS, 2016). O parecer pode recomendar o deferimento ou indeferimento da solicitação, ou ainda encaminhar diligências à solicitante. $O$ pedido de diligência é um recurso importante para o relator do processo, que pode servir para orientar a solicitante a corrigir eventuais equívocos ou omissões e apresentar mais informações necessárias para que o pedido possa ser eventualmente deferido, mas que também pode explicitar uma avaliação criteriosa, ou 
simplesmente impedir que o processo avance em um ritmo mais acelerado. Um ex-membro entrevistado apresenta o caráter simbólico desse recurso:

[Se] o produto não estava sendo avaliado de acordo com a expectativa da sua norma, dos seus princípios, então normalmente eu baixava em diligência. Porque a gente queria que o processo de avaliação de risco fosse uma questão relevante para o país, fosse uma prática coerente. Porque, como sociedade, como é que tu vai querer que um grupo mínimo de pessoas vai [sic] decidir em nome de 200 milhões, sem uma base científica sólida.

Assim, o parecer técnico é a materialização do modelo standard da ciência performado na CTNBio, na medida em que se apresenta como a peça central que sintetiza a análise científica do mérito do pedido em um único documento. Ele oferece aos membros decisores e à audiência externa a fundamentação científico-técnica para a decisão regulatória, que deve não apenas se basear no cumprimento das normas por parte da solicitante, mas também buscar "aliados" (Latour, 1987), como outras referências bibliográficas e pareceristas ad hoc para sustentar "tecnicamente" um determinado posicionamento. Os pareceres técnicos são o principal instrumento pelo qual os atores da CTNBio se colocam no papel de peritos neutros, que deliberam a partir de critérios técnicos e não políticos.

Além dos pareceres, os integrantes da comissão têm alguns recursos performáticos para essas discussões, que os auxiliam a reforçar o papel de peritos isentos, mas, por vezes, os levam a contestar a acuidade de alguns dos pareceres. Dentre esses recursos, incluem-se, evidentemente, o voto - favorável, contrário ou abstenção -, que é nominal e deve ficar registrado nos autos dos processos. Segundo o regimento interno, caso o parecer não seja aprovado por unanimidade pela plenária, ele deve ser publicado com a inclusão dos argumentos do voto divergente. Portanto, um único voto divergente, ainda que não tenha o poder de impedir determinada decisão, pode ser uma performance importante, pois pode servir para a publicidade de alguma eventual divergência no escrutínio dos processos. Um exemplo notório desse recurso é o parecer relativo à aprovação do primeiro milho transgênico da Monsanto. O texto apresenta, ao final, o voto divergente do então membro Rubens Nodari, que se posicionou contrariamente à liberação comercial com um elenco de 13 argumentos técnico-científicos, especialmente a respeito da ausência de estudos "sobre possíveis efeitos adversos ao meio ambiente nos ecossistemas brasileiros com as variedades brasileiras descendentes do MON810" (Brasil, 16 ago. 2007, p.18).

Além do voto, os integrantes podem também realizar um pedido de vistas, que retira a questão de pauta até a próxima reunião. Isso pode ter não apenas o intuito de efetivamente obter mais tempo para analisar o processo, mas, sobretudo, de explicitar a presença de divergências. Outro recurso performático é a enunciação e registro de uma determinada opinião, divergente ou convergente com o parecer, na ata da reunião deliberativa.

Existem situações em que os dois relatores selecionados para um processo oferecem posicionamentos que divergem substantivamente. Quando isso ocorre, é possível que a plenária vote pela consideração de apenas um dos dois pareceres e pela desconsideração do outro. Essa situação ocorreu no âmbito da reunião da subcomissão vegetal/ambiental presenciada em abril de 2016, quando a maioria da subcomissão votou por desconsiderar 
o parecer de um membro, representante do Ministério do Meio Ambiente (MMA), que apresentava um conjunto de diligências a uma solicitante de liberação planejada (experimental) de uma variedade de soja transgênica, e considerar apenas o parecer que não solicitava nenhuma diligência. De fato, esse episódio mostrou, também, como o próprio seguimento das resoluções normativas é mais um critério de disputa, na medida em que o primeiro parecerista defendia que a empresa solicitante não estava cumprindo o exigido pela própria resolução normativa da CTNBio relativa aos processos de liberação planejada, e o segundo parecerista, representante do Ministério da Agricultura, Pecuária e Abastecimento (Mapa), afirmava que a empresa cumpria sim os critérios da resolução normativa e que seria inexequível para a solicitante atender integralmente àquelas diligências apresentadas pelo outro parecerista. Por votação da maioria dos membros presentes, o parecer que pedia novas diligências foi descartado, e o processo seguiu para a votação em plenária com a consideração exclusiva do segundo parecer.

Assim, a discussão a respeito do parecer é também um momento performático, em que os membros que apresentam posicionamentos divergentes buscam, mais que convencer os seus pares sobre sua visão científica acerca do mérito da questão, torná-la pública para a audiência. Isso é feito a partir de fundamentações técnicas ou científicas, como a apresentação de estudos que contradizem ou reforçam as informações apresentadas, ou a alegação de que as informações apresentadas pelo requerente não atendem aos próprios critérios exigidos pelas resoluções normativas da CTNBio. É interessante notar que os integrantes da CTNBio, tanto os favoráveis como os mais críticos aos OGMs, esforçam-se para transmitir a imagem de que as discordâncias levantadas se dão, não devido a posicionamentos ideológicos ou políticos, mas estritamente em relação aos critérios e informações técnicas presentes no processo específico. No entanto, é comum, entre os próprios membros da CTNBio, a acusação de que os que discordam de um determinado posicionamento são movidos por ideologia ou influências das empresas, e não por critérios técnicos de biossegurança. Isso está presente, surpreendentemente, não apenas em declarações na imprensa, mas algumas vezes nos próprios pareceres, como é o caso do supracitado parecer de aprovação do pedido de liberação comercial do milho.

\section{A produção de inscrições}

Ainda que não esteja presente no regimento interno da CTNBio, é permitida a presença de público externo nas reuniões "desde que haja assentos disponíveis" (Inscrições..., s.d.). Não há transparência quanto ao critério de escolha dos participantes, e, na prática, a "limitação de assentos" torna-se uma ferramenta de controle da audiência. ${ }^{2}$ De fato, "a disponibilidade de assentos" e a escolha dela derivada de quem pode ou não participar das reuniões são formas evidentes de gestão de palco exercida pela secretaria executiva da CTNBio. Esse tópico já foi objeto de litígio, quando o Ministério Público ganhou uma liminar para garantir a presença de público externo nas reuniões deliberativas (CTNBio..., 15 maio 2007). Nas observações realizadas para esta pesquisa, a plateia presente nas reuniões consistia, sobretudo, de representantes das empresas de biotecnologia que têm pedidos em andamento, com a exceção de representantes do Ministério Público e do Instituto Brasileiro do Meio Ambiente e dos Recursos Naturais Renováveis (Ibama). Segundo um servidor da 
CTNBio entrevistado, o motivo da grande presença de representantes das empresas nas sessões deliberativas é o conhecimento imediato sobre as deliberações relativas a processos de interesse comercial, isto é, antes de que as comunicações oficiais cheguem à empresa, e, com isso, a possibilidade de antecipação da tomada de decisões estratégicas. Durante as reuniões, quando um item da pauta é a discussão ou deliberação sobre algum processo que envolve sigilo de informação comercial, o que está assegurado na própria lei n.11.105/2005, o público externo é solicitado a deixar a sala de reuniões, com exceção do representante da empresa ou instituição responsável pelo requerimento.

A CTNBio é obrigada por lei a publicar todas as informações relativas às suas atividades, com exceção daquelas informações que envolvem sigilo comercial. Mais que a apresentação oral nas sessões ordinárias, é por meio do registro que o membro performa o seu papel, não apenas durante a reunião, mas de forma perene em publicações no Diário Oficial da União e na página de internet da CTNBio. Nesta é possível encontrar não apenas os pareceres relativos a cada uma das decisões, mas também a pauta, as deliberações e a ata de cada uma das reuniões, assim como os nomes de todos os seus integrantes atuais e anteriores. A própria página da internet da CTNBio é um dos principais palcos de atuação, ${ }^{3}$ o que reforça o poder/materialidade dos documentos, especialmente os pareceres e as atas de reunião como peças performáticas, na medida em que poucas são as pessoas que de fato acompanham as performances in vivo na sala de reunião.

No entanto, as atas disponibilizadas na internet, por se apresentarem com centenas de páginas de transcrição, acabam sendo documentos áridos, que se tornam, mais do que fontes de publicidade, mecanismos de ocultação das dinâmicas internas. Já os pareceres, ao contrário, são documentos relativamente curtos, que apresentam um resumo das ponderações, e não os detalhes das informações submetidas pelas empresas e, sobretudo, das divergências ocorridas ao longo do processo (salvo nos casos em que se registra, como anexo e por uma exigência legal, os argumentos do voto divergente). O parecer publicado acaba por manter nos bastidores grande parte das disputas que envolveram a sua aprovação, apresentando-se como uma peça consensual e definitiva. Por exemplo, o parecer mencionado anteriormente, a favor de novas diligências a uma solicitante de liberação planejada, não foi publicado na página da CTNBio, pois não foi posteriormente discutido na plenária. Desse modo, essa divergência acabou sendo previamente ocultada.

Uma das características cruciais da "gestão de palco" que mantém o funcionamento estável da CTNBio é, paradoxalmente, a ocultação das performances aqui discutidas para um público abrangente, não apenas devido ao limitadíssimo acesso às reuniões (normalmente é permitida a presença de 15 a vinte pessoas de fora), mas também pela natureza das próprias inscrições processuais, que restringe a publicidade das discussões e divergências aos registros nas atas. Na prática, a comissão leva o espaço-tempo das reuniões, que institucionalmente deveria funcionar como um palco, para os bastidores.

\section{O palco estendido e a atuação das plateias: a consolidação do modelo standard}

Ainda que a maior parte das performances não seja de fato conhecida para além da plateia restrita discutida anteriormente, em algumas ocasiões é possível identificar uma 
extensão do palco da CTNBio para outras esferas. Isso ocorre quando seus membros ou exmembros vão a público, em eventos científicos, publicações e, em especial, em entrevistas e intervenções na mídia, a fim de reforçar ou criticar o papel performado pela comissão ou por parte de seus integrantes. Isso foi feito recorrentemente, tanto pelos que buscam afirmar a legitimidade de determinadas decisões, e sobretudo a adequação do regime de regulação centralizado na CTNBio, como por aqueles que buscam confrontar as decisões e acusar a fragilidade da política de biossegurança nacional.

Assim, é principalmente a partir da extensão do palco que as plateias cumprem papéis importantes, que não se encontram registrados nos ritos processuais da CTNBio. Em resumo, os públicos têm quatro possíveis papéis a cumprir: o de espectador, o de participante nas reuniões da CTNBio, o de crítico ou contestador e o de atuação nos bastidores. O primeiro, o papel clássico do público no modelo standard da ciência, é o de um espectador passivo, que apenas assiste e respeita a deliberação tomada pelos membros da CTNBio. Essa passividade pode ser, no entanto, uma legitimação intencional por parte do público da autoridade epistêmica e política do colegiado. A manifestação a favor da autoridade e da legitimidade da decisão contribui ativamente para a aceitação de decisões políticas, e, não por acaso, diante da ampla liberação comercial de novos OGMs, são promovidas reiteradamente por parte da aliança favorável aos transgênicos.

O público, ou a audiência, pode também buscar opinar legalmente sobre deliberações por meio da interação direta com os membros da CTNBio. Isso pode ocorrer de duas formas. A primeira é a presença "assegurada" nas discussões e a permissão para explicitar um determinado posicionamento, mas sem direito a voto. Outra forma mais direta é a participação em audiência pública, que, segundo o regimento, também pode oferecer fundamentos para os pareceres e para as deliberações. A partir de uma decisão judicial que obrigou a CTNBio a realizar uma audiência pública para a aprovação do primeiro milho transgênico (MP vai entrar..., 19 mar. 2007), a CTNBio adotou o padrão de realizar audiências públicas para se discutir a aprovação comercial de novas espécies de OGM. Até o momento, foram realizadas cinco audiências públicas, relativas à aprovação de espécies transgênicas de milho, algodão, eucalipto, feijão e cana-de-açúcar. Os documentos apresentados ficam disponíveis no site da comissão (Audiências..., s.d.). Assim, as audiências públicas são a principal oportunidade para que membros externos do público possam registrar posicionamentos, convergentes ou divergentes, nos autos processuais da CTNBio.

Outra possibilidade performática das audiências é a explicitação de crítica ou oposição. Isso tem ocorrido basicamente de duas maneiras: a ação judicial e a manifestação pública. A primeira foi a principal ferramenta utilizada antes da aprovação da nova lei, e é possível indicar que, durante esse período, foi muito bem-sucedida, na medida em que decisões judiciais diversas suspenderam as decisões da CTNBio e colocaram em xeque a sua soberania e legitimidade (Lima, 2011). A partir da aprovação do novo arcabouço legal, essa estratégia foi inicialmente também muito utilizada, tendo sido bem sucedida em alguns episódios, como o da suspensão da liberação comercial do milho até que se aprovassem as regras de coexistência (Zanoni et al., 2011), mas ela foi gradualmente perdendo força, uma vez que a nova lei propiciou uma efetiva estabilização legal da autoridade deliberativa da CTNBio. Assim, a manifestação pública tornou-se, a partir da perda de eficácia do litígio judicial, um 
dos principais dispositivos performáticos por parte da audiência que se opõe ao processo de transgenização possibilitado pela CTNBio. Em algumas ocasiões, isso ocorreu a partir de mobilizações sociais para a produção de atos simbólicos, não apenas durante as próprias reuniões deliberativas da CTNBio, por meio de invasão de manifestantes e a inviabilização de seu prosseguimento, mas também em outras instâncias, como, por exemplo, quando a empresa Susano Celulose teve seus laboratórios danificados num ato de protesto contra a aprovação do eucalipto transgênico (MST..., 5 mar. 2015).

Na medida em que a possibilidade de manifestação por meio da divergência científica fica razoavelmente confinada nas paredes e na documentação produzida pela CTNBio, e o litígio jurídico perde eficácia com a entrada em vigor da nova lei, são estas técnicas performáticas por parte da oposição aos OGMs aquelas que obtêm maior sucesso de visibilidade midiática. Por outro lado, são também estes os momentos em que os membros da CTNBio que endossam as decisões favoráveis aos OGMs também mais se utilizam de outros palcos, como a publicação de artigos na imprensa para reiterar a imagem de que tais protestos são infundados e que as deliberações se dão a partir de uma análise criteriosa e transparente.

Outro tipo de performance adotada para a contestação é a publicação técnico-científica por parte da coalizão contrária, como as publicações do Núcleo de Estudos Agrários e Desenvolvimento Rural (Nead), órgão do extinto Ministério do Desenvolvimento Agrário, que se tornou uma das principais vozes de oposição à atuação da CTNBio (Ferment et al., 2015; Zanoni, 2004; Zanoni, Ferment, 2011). Por exemplo, o Nead publicou um documento apresentando estudos científicos que contradizem as prescrições da resolução normativa sobre coexistência de milho (Ferment et al., 2009) e, mais recentemente, uma publicação com mais de 750 referências de revistas científicas que contestam o suposto consenso científico acerca da segurança dos transgênicos (Ferment et al., 2015). Deve-se salientar, também no contexto dos grupos que persistem em oposição ao processo de transgenização, a estratégia de buscar outros espaços de resistência epistêmica, especialmente a denúncia dos impactos dos agrotóxicos (Carneiro et al., 2015), e o fortalecimento do movimento agroecológico (Altieri, 2002) como alternativa ao modelo da agricultura industrial associada aos OGMs.

Da mesma forma, a coalizão favorável mobiliza publicações científicas internacionais e nacionais diversas que corroboram os protocolos e as decisões estabelecidas, como as normas de coexistência aprovadas (Andrade et al., 2009).

Por fim, e talvez o mais importante, as audiências podem executar ações nos bastidores, onde os atores não precisam expor publicamente determinados posicionamentos, mas pressionam para que seus interesses sejam atendidos. Conforme aponta Goffman (2004), os bastidores são tão importantes quanto o palco, o controle sobre o que deve ser visto e o que deve ser ocultado é crucial para o sucesso ou o fracasso da peça. Evidentemente, é esse o padrão adotado pelas empresas de biotecnologia, que raras vezes se posicionam explicitamente a respeito das decisões, mas que buscam fazê-lo por diversos outros canais. Justamente por estarem nos bastidores, eles não são rastreáveis com facilidade, mas, ainda assim, é possível apontar algumas estratégias visivelmente adotadas. Uma delas é o financiamento e controle de instituições que servem como porta-vozes, como o Conselho 
de Informações em Biotecnologia (CIB) (Sobre..., s.d.), mas são também conhecidas a criação de prêmios (Prêmio agroambiental..., 20 mar. 2012), o financiamento a centros e grupos de pesquisa (Ribeiro, 2000) e o lobby parlamentar (Carneiro, 12 maio 2014). É justamente a manutenção dessas atuações nos bastidores, isto é, o exercício de influência velada sobre as decisões da CTNBio, um dos principais mecanismos pelos quais se assegura a manutenção da imagem de que as decisões favoráveis não são motivadas por pressões políticas ou econômicas.

\section{As dinâmicas de votação: o controle do recurso performático}

Uma análise qualitativa sobre o histórico das votações a respeito de liberações comerciais realizada no âmbito desta pesquisa indica uma correlação dos posicionamentos técnicocientíficos apresentados pelos cientistas com os históricos posicionamentos políticoeconômicos apresentados pelos ministérios que os indicaram. Identificamos uma polarização entre dois grupos de cientistas-membros que reproduz a polarização entre duas coalizões heterogêneas no país antes da aprovação da nova Lei de Biossegurança (Guivant, 2002, 2009). Por um lado, há um grupo majoritário, formado por cientistas vinculados sobretudo às áreas de biotecnologia e agronomia, indicados por ministérios que historicamente se manifestaram a favor de uma regulação mais permissiva em relação à introdução de OGM, especialmente na agricultura. Por outro, um grupo minoritário, de cientistas ligados às áreas de saúde pública, meio ambiente e agricultura familiar, representantes de ministérios que também se consolidaram historicamente como membros da aliança de atores contrários ao processo de transgenização da agricultura brasileira que, no âmbito da CTNBio, costumam posicionar-se mais próximos da defesa do princípio de precaução.

Há oito membros definidos por ministérios ou representativos de grupos sociais que historicamente tenderam a adotar uma postura de maior resistência à aprovação comercial de OGMs. São eles: os dois representantes definidos pelo Ministério do Desenvolvimento Agrário (MDA), os dois representantes definidos pelo MMA, o especialista em defesa do consumidor, o especialista em saúde do trabalhador, além dos dois representantes definidos pelo Ministério da Saúde (MS). Por outro lado, é possível identificar uma atitude mais receptiva aos transgênicos entre os 14 membros definidos pelo MCTIC, que historicamente se posicionou a favor da tecnologia, além dos definidos pelo Ministério do Desenvolvimento, Indústria e Comércio Exterior (MDIC) e Ministério da Agricultura, Pecuária e Abastecimento (Mapa), que reforçam o discurso de inexorabilidade desse sistema para o desenvolvimento econômico, totalizando um grupo de 16 membros potencialmente favoráveis. Assim, dentre as "detentoras" das cadeiras da CTNBio, apenas as pastas do Ministério da Defesa (MD), Secretaria da Aquicultura e Pesca (SAP) e Ministério das Relações Exteriores (MRE) não tiveram uma atuação prévia destacada em relação aos transgênicos. No entanto, os representantes desses três ministérios também têm reiterado um posicionamento favorável às liberações comerciais de transgênicos.

Segundo Leonardo Melgarejo, (citado em Thuswohl, 14 nov. 2013, s.p.) ex-membro da CTNBio representante do MDA, há uma clara associação entre a representação política do integrante e seu posicionamento técnico-científico sobre os pareceres: 
Na maior parte dos casos em que eu participei, o Ministério da Saúde, o Ministério do Meio Ambiente e o Ministério do Desenvolvimento Agrário têm dito que esses estudos não são suficientes, que mais pesquisas são necessárias. Mas outros membros da CTNBio, representantes do Ministério da Agricultura, do Ministério da Indústria e Comércio e do Ministério das Relações Exteriores, entre outros, têm dito que os estudos produzidos pelas empresas são suficientes.

O Gráfico 1 mostra a composição da CTNBio, de acordo com a associação da representatividade política com as posturas históricas em relação à tecnologia do OGM.

Gráfico 1: Composição política da CTNBio a partir do cruzamento de critérios de representação e indicação com o posicionamento histórico em relação à controvérsia

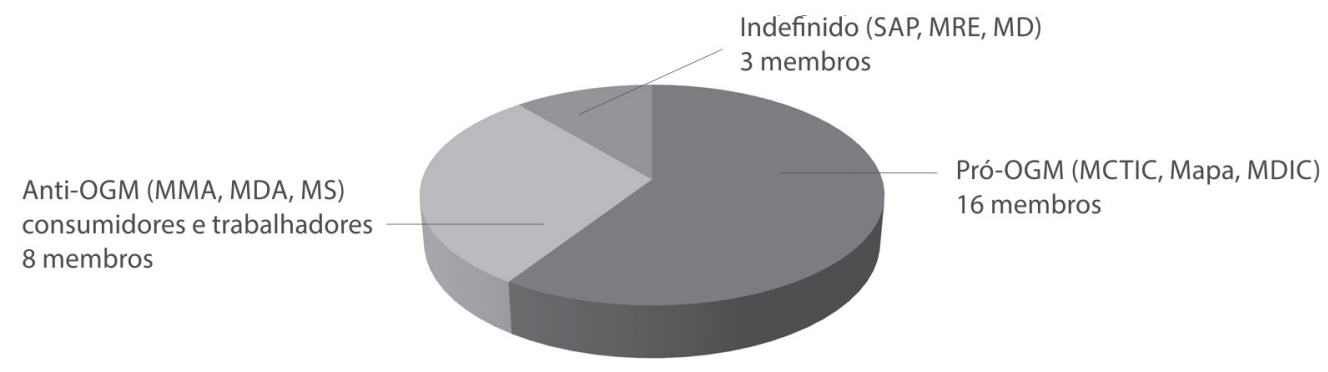

Fonte: elaborado pelos autores.

É possível identificar que a polarização política que precedia a estabilização constitucional da legislação proporcionada pela lei n.11.105/2005 é também reproduzida na forma de polarização técnico-científica no âmbito da CTNBio. A comissão passou a ser o palco central para a disputa entre as coalizões favorável e contrária aos transgênicos, cada qual associada a distintos ministérios que historicamente se posicionaram em relação à controversa introdução dos transgênicos no país. Por exemplo, a exigência de estudos aprofundados de impacto ambiental por parte do MMA é antagônica à defesa dos transgênicos como avanço inexorável da ciência adotada pelo MCTIC, ou do papel crucial dessa tecnologia para a produtividade agrícola adotada pelo Mapa. O cientista indicado pelo MMA tende a desempenhar o papel que corresponde a uma personagem crítica aos transgênicos, enquanto aquele indicado pelo Mapa apresenta-se como um cientista entusiasta da tecnologia. Um membro da CTNBio entrevistado para esta pesquisa, quando indagado sobre como se dá o processo de definição dos representantes da comunidade científica por parte do MCTIC, relata:

Nós não sabemos como é que eles fazem. Nós tentamos descobrir, é muito difícil. ... Mas, via de regra, é $100 \%$, assim, não é nem uma pessoa... não vou dizer que não tenha independência de pensar, pode ter em outras coisas, mas nesse tema, eles vêm determinados a votar em bloco a favor e não importa, não importam os argumentos. [Durante] vários anos, raramente houve uma pessoa escolhida pelo MCTIC que pensa o contrário. 
Ademais, a regulamentação inicial da lei n.11.105/2005 previa que as deliberações da CTNBio deveriam ser aprovadas por maioria qualificada, isto é, por pelo menos $2 / 3$, ou 18 , de seus 27 membros. Nos primeiros anos de operação desse modelo, ficou evidente que a necessidade de aprovação por esses $2 / 3$ do colegiado, associada à composição dos integrantes da CTNBio, estava inviabilizando as aprovações de liberações comerciais. Aproximadamente 1/3 dos membros da CTNBio, indicados por ministérios e setores da sociedade politicamente contrários à aceitação dos riscos e impactos socioambientais associados à monocultura de lavouras transgênicas, apresentam votos que reiteram posicionamentos a favor de mais estudos de impacto e de menor concordância com as análises de risco favoráveis à liberação comercial de novas variedades de plantas transgênicas, o que na prática se traduziu em nenhum processo de liberação comercial aprovado.

$\mathrm{Na}$ imprensa, sobretudo a partir de 2007, passa a ter espaço o debate levado a cabo pelos próprios membros da CTNBio, com menções a ações de lobby, nos bastidores, para que o Congresso aprovasse e o presidente sancionasse uma nova regulamentação para a CTNBio (Thuswohl, 14 dez. 2006) que estabelecesse a maioria simples para aprovação. Isso aconteceu em 2007 (Brasil, 21 mar. 2007). Com essa mudança, que passou de um mínimo de 18 para 14 votos favoráveis, a CTNBio começou a aprovar as liberações comerciais. Desde então até o final de 2016, nenhum pedido foi indeferido e se aprovou a liberação comercial de 56 variedades geneticamente modificadas de plantas (incluindo soja, milho, algodão, eucalipto e feijão), 26 vacinas, um mosquito Aedes aegypti e dez micro-organismos diversos.

Portanto, a coalizão favorável aos transgênicos foi a vencedora, na medida em que a restruturação da lei não apenas lhe assegurou o controle dos processos deliberativos, mas também o controle administrativo da CTNBio e da secretaria executiva, o que se reflete no regime sistemático de liberações comerciais implementado a partir da mudança do quórum mínimo de aprovação das deliberações.

\section{A consolidação do modelo standard de ciência na CTNBio}

Se é possível inferir que a mudança para a aprovação por maioria simples consistiu em uma estratégia bem-sucedida para a neutralização da influência da coalizão contrária ao processo de transgenização dentro da CTNBio, talvez o mais interessante é que a polarização entre os dois grupos no âmbito técnico-científico sugere uma ruptura com a performance esperada de acordo com o modelo standard de ciência associado à nova legislação.

Essa divisão interna pode ser compreendida como parte de um grave conflito na imagem de um colegiado científico inter e transdisciplinar, onde cada campo do conhecimento contribui para a análise dos riscos. A polarização pode indicar que, ou alguns dos membros não são suficientemente "científicos" ou não há de fato consenso científico sobre a biossegurança dos OGMs. Os defensores das decisões têm argumentado que os integrantes da comissão que se opõem explicitamente à tecnologia transgênica não apresentam argumentos científicos, mas são movidos por motivos políticos e ideológicos (Transgênicos..., 27 nov. 2006). Paralelamente, aqueles que contestam as aprovações apontam que a ala majoritária 
da comissão ignora evidências científicas e é, da mesma forma, movida por posições políticas e ideológicas (Thuswohl, 14 nov. 2013). Independentemente do mérito de cada posição, essa divisão e o antagonismo de algumas das disputas internas podem sugerir que, ao contrário do que se projetou na nova legislação, a CTNBio não é uma comissão isenta de influências de posicionamentos ideológicos, mas suas dinâmicas internas traduzem as disputas políticas que ocorrem em um nível social mais amplo. Nesse sentido, um servidor da secretaria executiva entrevistado por nós, coloca:

A minha impressão é que existe uma militância de certa forma ideológica em torno destes processos. Um sentimento do conflito entre o privado e o público, o natural e o artificial. ... Então há um conflito ideológico, histórico, que perpassa as discussões, os argumentos sobre as questões dos produtos examinados aqui. Então você tem todo um legado histórico sobre essa coisa. As pessoas são apaixonadas por este assunto e defendem os seus pontos de vista, suas paixões, no contexto dessas discussões. E seguem a lógica, sua cartilha, das suas convicções de formação. ... Eu estou falando do interno [à comissão], não do externo.

No entanto, conforme temos observado, a estabilidade da CTNBio não tem se deteriorado, pelo contrário, parece ter adquirido uma inédita consolidação institucional. As performances têm tido sucesso no que concerne à "purificação" do debate, isto é, a manutenção das disputas políticas nos bastidores. Isso tem sido possível justamente pelas exigências do script performático da CTNBio e pelas estratégias de gestão de palco discutidas anteriormente, que acabam por ocultar os conflitos e divergências. Tanto as posições contrárias quanto as favoráveis aos transgênicos devem apelar ao discurso científico, numa outra dimensão do confronto, para adentrarem com legitimidade o palco de disputa. Os argumentos técnicos e científicos são os que ficam registrados nos pareceres e atas da CTNBio, e, em última instância, a política explícita tem se traduzido em uma política implícita às argumentações técnico-científicas. Ainda assim, enquanto na comunidade científica ainda permanecem divergências (Hilbeck et al., 2015; Krimsky, 2015), na comissão a coalizão pró-transgênicos ganhou o poder de decisão, enquanto a coalizão contrária aos transgênicos ganhou apenas o direito de se manifestar no palco interno da CTNBio.

Uma pergunta fundamental para a compreensão sobre como, apesar das fragilidades apontadas, além de outras que, por motivos de espaço, não caberiam ser aqui discutidas (Zanoni et al., 2011), a CTNBio não tem enfrentado uma erosão de sua estabilidade é: quem é o público que acompanha efetivamente essas representações? É importante lembrar que a maioria da sociedade brasileira não tem acesso às dinâmicas de deliberação e aos pareceres técnicos da CTNBio. A sua audiência é formada por alguns poucos espectadores, que não incluem os consumidores do final da cadeia (apenas a representação do Instituto de Defesa do Consumidor na comissão, que faz parte do grupo de votos vencidos), mas atores diretamente interessados na sua produção e, em menor escala, fiscalização. Um indicativo desse público é, conforme relatado acima, a lista dos presentes nas sessões deliberativas. Quem acompanha presencialmente as sessões são, sobretudo, representantes da cadeia de empresas de biotecnologia, mas também representantes de outros órgãos do Governo Federal e do Ministério Público. Ou seja, as audiências da CTNBio são essencialmente 
formadas pelos atores historicamente ativos nas coalizões mais amplas favorável e contrária aos transgênicos.

Nesse contexto, é a coalizão opositora aquela que tem apresentado críticas à atuação da CTNBio (Zanoni et al., 2011), mas tendo em vista sua perda de poder de litígio jurídico a partir da estabilização legislativa propiciada pelo novo marco regulatório, suas críticas não reverberam para além das suas tradicionais audiências, isto é, os seus próprios integrantes. Nelkin (1992), ao tipificar controvérsias científicas, aponta que uma das armas mais eficazes de mobilização da opinião pública é o litígio judicial. Da mesma forma, as técnicas de representação mais poderosas dos críticos eram os litígios judiciais bem fundamentados na inconstitucionalidade dos atos da comissão. Com o fim dessa possibilidade, a performance dos críticos se tornou menos visível e impactante. De fato, um dos servidores da secretaria executiva entrevistados para esta pesquisa corrobora a percepção de que o conflito não mais se dá no palco jurídico, mas na própria CTNBio:

A controvérsia continua, só que não há conflitos jurídicos, porque a lei disciplinou juridicamente a competência de cada um dos órgãos. Então a lei foi mais bem elaborada do ponto de vista jurídico, e por isso os conflitos jurídicos que se arrastam na justiça por décadas por questões legais estão menos aflorados. Mas a controvérsia existe ainda, existe a discussão. A diferença de opinião, de pontos de vista, ela ainda floresce dentro da comissão.

Por outro lado, conforme discutimos anteriormente, a cultura política brasileira tem menor propensão a uma crítica explícita à autoridade dos sistemas de peritos e do conhecimento técnico-científico. Um índice de confiança nas profissões elaborado pelo Centro de Gestão e Estudos Estratégicos (CGEE, 2015) apresenta o "cientista de universidade ou de instituição públicas de pesquisa" como o profissional mais respeitado, acima de médico, escritor e mesmo "representante de movimento ambientalista", dado que foi reiterado nas três enquetes realizadas desde 2006.

Assim, essa cultura política contribuiria, conjuntamente com o confinamento das divergências político-científicas dentro dos bastidores da comissão, para blindar a CTNBio de expor suas próprias rupturas de representação. Com o fim dos litígios judiciais e a restrição das performances ao script da CTNBio, a politização das deliberações técnicas da CTNBio fica invisível para a população.

\section{Considerações finais}

A partir da análise da CTNBio como uma dramaturgia, foi possível entender a relevância do controle sobre os bastidores - e especialmente sobre a imagem de ciência pura que se logra transmitir a partir disso - para o bom desempenho das performances de instituições da ciência regulatória brasileira. A estabilização da CTNBio como órgão ao mesmo tempo consultivo, regulatório e gestor é algo sui generis entre as instituições de ciência regulatória. Esta pesquisa sugere que a consolidação da centralização das competências regulatórias e avaliadoras na comissão ocorre ao longo de um processo de limitação da publicidade das divergências às possibilidades performáticas do palco da CTNBio. As performances acessíveis a 
um público mais amplo são sobretudo pareceres e atas de reunião, que ocultam, movem para os bastidores, as divergências técnico-científicas-político-ideológicas entre seus membros. Esse público só tem acesso ao discurso já purificado por meio do script performático da CTNBio, que transmite eficientemente a imagem de que o que está sendo executado é o modelo standard de ciência.

Entretanto, esta análise das dinâmicas internas da CTNBio mostra que, por mais que os seus integrantes se esforcem para passar uma imagem de que as decisões são fundamentadas em critérios rigorosamente técnicos, esses próprios critérios não são definidos sem disputas políticas. Nesse sentido, a perene cisão entre os 27 membros do colegiado, no qual dois blocos se acusam mutuamente de estarem movidos por interesses ideológicos e não científicos, é talvez um dos mais claros indicativos de que uma comissão técnica não pode deixar de operar a partir de disputas políticas. Segundo esta análise, as performances da CTNBio, sobretudo em virtude de sua própria divisão interna, corroboram a premissa de que a política não se mantém isolada do lado de fora das portas das reuniões deliberativas, mas que é exercida justamente entre os seus pares, por meio de argumentos técnicos e processuais.

Por outro lado, além do confinamento da controvérsia político-científica dentro da CTNBio - auxiliado pelo maior poder da coalizão favorável, que manteve o controle de sua gestão de palco -, a nova Lei de Biossegurança acarretou a inviabilização do litígio jurídico, o que contribuiu para a remoção dos conflitos para os bastidores. Isto, aliado a uma cultura política menos crítica à autoridade dos sistemas de peritos, tem permitido que as fragilidades do modelo standard, baseado na separação entre fatos e valores, sejam conhecidas apenas pelas audiências das próprias coalizões, permanecendo invisíveis para o público leigo mais abrangente e para a agenda de entidades políticas e midiáticas. Portanto, o aparente sucesso do modelo standard implementado nessa instância da ciência regulatória brasileira está relacionado com a eficácia, por parte da coalizão vencedora, em garantir que as divergências político-científicas não ultrapassem as paredes - e os bastidores - do "teatro da CTNBio".

\section{AGRADECIMENTO}

O presente trabalho foi realizado com apoio da Coordenação de Aperfeiçoamento de Pessoal de Nível Superior - Brasil (Capes). Código de financiamento 001.

\section{NOTAS}

${ }^{1}$ Nesta e nas demais citações de textos em inglês, a tradução é livre.

${ }^{2}$ Um dos autores deste artigo teve, durante o período desta pesquisa, três pedidos negados, por "indisponibilidade de assentos", sem a informação de quantos foram os inscritos e quais foram os critérios de eleição dos selecionados.

${ }^{3}$ A lei n.11.105/2005 prevê a criação do Sistema de Informações em Biossegurança (SIB), que deveria integrar todas as informações relacionadas à biossegurança, incluindo as informações relativas aos órgãos fiscalizadores e ao CNBS. No entanto, esse sistema nunca foi efetivamente criado. A CTNBio apresenta as suas informações mandatoriamente públicas em sua página de internet. 


\section{REFERÊNCIAS}

ALTIERI, Miguel A.

Agroecologia: bases científicas para uma agricultura sustentável. Guaíba: Agropecuária. 2002.

ANDRADE, Paulo Paes de et al. Milho geneticamente modificado: bases científicas das normas de coexistência entre cultivares. Brasília: Ministério da Ciência e Tecnologia. 2009.

\section{AUDIÊNCIAS...}

Audiências públicas. Disponível em: <http:// ctnbio.mcti.gov.br/participacao-publica $>$. Acesso em: 6 mar. 2017. s.d.

BECK, Ulrich.

Risk society: towards a new modernity. London: Sage. 1992.

BRASIL.

Ministério de Ciência e Tecnologia. Comissão Técnica Nacional de Biossegurança. Parecer técnico n.1.100/2007. Processo n.01200.002995/1999-54 Disponível em: <http://ctnbio.mcti.gov.br/liberacao-comercial/ liberacao-comercial/consultar-processo $>$. Acesso em: 12 jan. 2018. 16 ago. 2007.

\section{BRASIL.}

Lei n.11.460. Dispõe sobre o plantio de organismos geneticamente modificados em unidades de conservação; acrescenta dispositivos à lei n.9.985, de 18 de julho de 2000, e à lei n.11.105, de 24 de março de 2005; revoga dispositivo da lei n.10.814, de 15 de dezembro de 2003; e dá outras providências. Disponível em: <http://www.planalto.gov.br/ ccivil_03/_Ato2007-2010/2007/Lei/L11460. htm>. Acesso em: 30 jan. 2019. 21 mar. 2007.

BRASIL.

Ministério de Ciência e Tecnologia. Portaria MCT n.146, de 6 de março de 2006. Disponível em: <http://ctnbio.mcti.gov.br/regimentointerno-da-ctnbio>. Acesso em: 11 abr. 2017. 6 mar. 2006.

BRASIL.

Lei n.11.105. Regulamenta os incisos II, IV e V do $§ 10$ do art. 225 da Constituição Federal, estabelece normas de segurança e mecanismos de fiscalização de atividades que envolvam organismos geneticamente modificados (OGM) e seus derivados, cria o Conselho Nacional de Biossegurança (CNBS), reestrutura a Comissão Técnica Nacional de Biossegurança (CTNBio), dispõe sobre a Política Nacional de Biossegurança (PNB), revoga a lei n.8.974, de 5 de janeiro de 1995, e a Medida Provisória n.2.191-9, de 23 de agosto de 2001, e os arts.
$5,6,7,8,9,10$ e 16 da lei n.10.814, de 15 de dezembro de 2003 , e dá outras providências. Disponível em: <http://www.planalto.gov.br/ ccivil_03/_ato2004-2006/2005/lei/111105.htm>. Acesso em: 11 abr. 2017. 24 mar. 2005.

BRASIL.

Lei n.8.974. Regulamenta os incisos II e V do $\S 1^{\circ}$ do art. 225 da Constituição Federal, estabelece normas para o uso das técnicas de engenharia genética e liberação no meio ambiente de organismos geneticamente modificados, autoriza o Poder Executivo a criar, no âmbito da Presidência da República, a Comissão Técnica Nacional de Biossegurança, e dá outras providências. Disponível em: < http:// www.planalto.gov.br/ccivil_03/leis/L8974.htm>. Acesso em: 11 abr. 2017. 5 jan. 1995.

CARNEIRO, Fernando Ferreira et al.

Dossiê Abrasco: um alerta sobre os impactos dos agrotóxicos para a saúde. Rio de Janeiro: Escola Politécnica de Saúde Joaquim Venâncio; São Paulo: Expressão Popular. 2015.

CARNEIRO, Mariana.

Empresas articulam lobby para simplificar acesso à tecnologia. Folha de S. Paulo.

Disponível em: <http://www1.folha.uol.com.br/ mercado/2014/05/1452853-empresas-articulamlobby-para-simplificar-acesso-a-tecnologia. shtml>. Acesso em: 15 mar. 2017. 12 maio 2014.

CGEE.

Centro de Gestão e Estudos Estratégicos. Percepção pública da ciência e tecnologia 2015: ciência e tecnologia no olhar dos brasileiros: sumário executivo. Brasília: CGEE. 2015.

CTNBIO..

CTNBio: sessões abertas são mantidas pela Justiça. Ministério Público Federal. Disponível em: <http://www.mpf.mp.br/df/sala-deimprensa/noticias-df/ctnbio-sessoes-abertas-saomantidas-pela-justica>. Acesso em: 27 fev. 2017. 15 maio 2007.

FERMENT, Gilles et al.

Lavouras transgênicas: riscos e incertezas: mais de 750 estudos desprezados pelos órgãos reguladores de OGMs. Brasília: Ministério do Desenvolvimento Agrário. 2015.

FERMENT, Gilles et al.

Coexistência: o caso do milho. Proposta de Revisão da Resolução Normativa n.4 da CTNBio. Brasília: Ministério de Desenvolvimento Agrário. 2009.

GOFFMAN, Erving.

A representação do eu na vida cotidiana.

Petrópolis: Vozes. 2004. 
GUIVANT, Julia S.

Governance of GMO and the constraints for a redefinition of the public arena in Brazil. In: Dasgupta, Samir (Ed.). Understanding the global environment. Delhi: Pearson. 2009.

GUIVANT, Julia S.

Transgênicos no Brasil: a necessidade de debater a governança de novas tecnologias. In: Leite, José Rubens Morato; Fagúndez, Paulo Roney Avila (Org.). Aspectos destacados da Lei de Biossegurança na sociedade de risco. Brasília: Conceito Editorial. 2007.

GUIVANT, Julia S.

Transgênicos e percepção pública da ciência no Brasil. Ambiente e Sociedade, v.9, n.1, p.81-103. 2006.

GUIVANT, Julia. S.

A governança dos riscos e os desafios para a redefiniçao da arena pública no Brasil. In: Miranda, Marcio et al. (Org.). Ciência, tecnologia e sociedade: novos modelos de governança. Brasília: Centro de Gestão e Estudos Estratégicos. p.47-85. 2005.

GUIVANT, Julia S.

Heterogeneous and unconventional coalitions around global food risks: integrating Brazil into the debates. Journal of Environmental Policy and Planning, v.4, n.3, p.231-245. 2002.

GUIVANT, Julia S.; MACNAGTHEN, Phil. An analysis of the GM crop debate in Brazil. In: Macnaghten, Phil; Carro-Ripalda, Susana (Ed.) Governing agricultural sustainability. London: Routledge. 2015.

HILBECK, Angelika et al.

No scientific consensus on GMO safety. Environmental Sciences Europe, v.27, n.4, p.1-6. 2015.

HILGARTNER, Stephen.

The credibility of science on stage. Social Studies of Science, v.34, n.3, p.443-452. 2004.

HILGARTNER, Stephen.

Science on stage: expert advice as public drama. Stanford: Stanford University Press. 2000.

INSCRIÇÕES...

Inscrições para as reuniões da CTNBio. Disponível em: <http://ctnbio.mcti. gov.br/comunicados1/-/asset_publisher/ Uht2qGSWGC8b/content/inscricoes-para-asreunioes-da-ctnbio-?redirect=/inicio $\&>$. Acesso em: 27 fev. 2017. s.d.

JAMES, Cliver.

20th anniversary (1996 to 2015) of the Global Commercialization of Biotech Crops and Biotech Crop Highlights in 2015. ISAAA Brief, n.51, p.32-42. 2015.
JASANOFF, Sheila.

Designs on nature: science and democracy in Europe and the United States. New Jersey: Princeton University Press. 2005.

JASANOFF, Sheila.

Procedural choices in regulatory science.

Technology in Society, v.17, n.3, p.279-293. 1995.

JASANOFF, Sheila.

The fifth branch: science advisers as

policymakers. Cambridge, MA: Harvard

University Press. 1990.

JOLY, Pierre-Benoit.

Les OGM entre la science et le public? Quatre modèles pour la gouvernance de l'innovation et des risques. Economie Rurale, v.266, n.1, p.11-29. 2001.

KRIMSKY, Sheldon.

An illusory consensus behind GMO health assessment. Science, Technology and Human Values, v.40, n.6, p.883-914. 2015.

LATOUR, Bruno.

Science in action: how to follow scientists and engineers through society. Cambridge, MA: Harvard University Press. 1987.

LAW, John.

On sociology and STS. The Sociological Review, v.56, n.4, p.623-649. 2008.

LIMA, Marcia Tait.

Tecnociencia e cientistas: cientificismo e controvérsias na política de biossegurança brasileira. São Paulo: Annablume. 2011.

LIXO...

Lixo transgênico. Folha de S. Paulo. Editoriais. Disponível em: <http://www1.folha.uol.com.br/ fsp/opiniao/fz1012200902.htm>. Acesso em: 18 abr. 2017. 10 dez. 2009.

MACNAGHTEN, Phil; GUIVANT, Julia.

Converging citizens? Nanotechnology and the political imaginary of public engagement in Brazil and the United Kingdom. Public Understanding of Science, v.20, n.2, p.207-220. 2011.

MARCUS, George E.

Ethnography in/of the world system: the emergence of multi-sited ethnography. Annual Review of Anthropology, v.24, n.1, p.95-117. 1995.

MP vai entrar...

MP vai entrar com ação para anular audiência pública da CTNBio. Greenpeace. Disponível em: <http://www.greenpeace.org/brasil/pt/Noticias/ mp-vai-entrar-com-a-o-para-an/>. Acesso em: 6 mar. 2017. 19 mar. 2007.

MST...

MST invade empresa de eucalipto transgênico da Suzano e votação sobre liberação é 
adiada. Reuters. Disponível em: <http:// br.reuters.com/article/businessNews/ idBRKBNOM12IL20150305>. Acesso em: 6 mar. 2017. 5 mar. 2015.

NAS.

National Academies of Sciences, Engineering, and Medicine. Genetically engineered crops: experiences and prospects. Washington, DC: The National Academies Press. 2016.

NELKIN, Dorothy.

Controversy: politics of technical decisions. London; New York: Sage. 1992.

PRÊMIO AGROAMBIENTAL...

Prêmio Agroambiental Monsanto chega a sua terceira edição trazendo novidades. Monsanto. Disponível em: <http://www.monsanto.com/ global/br/noticias/pages/premio-agroambientalmonsanto-chega-a-sua-terceira-edicao-trazendonovidades.aspx>. Acesso em: 15 mar. 2017. 20 mar. 2012.

RIBEIRO, Maria Teresa Franco. A redefinição das agendas dos centros de P\&D: os limites do mercado na sinalização das áreas estratégicas. Revista de Administração Contemporânea, v.4, n.2, p.87-107. 2000.

SECRETARIA...

Secretaria Executiva. Disponível em: <http:// ctnbio.mcti.gov.br/secretaria-executiva $>$. Acesso em: 27 jan. 2017. s.d.

SOBRE...

Sobre o CIB. Disponível em: <http://cib.org.br/ sobre-o-cib/>. Acesso em: 15 mar. 2017. s.d.

THUSWOHL, Maurício.

Influência sobre CTNBio é trunfo das gigantes da transgenia. Repórter Brasil. Disponível em: <http://reporterbrasil.org.br/2013/11/ influencia-sobre-ctnbio-e-trunfo-das-gigantesda-transgenia/>. Acesso em: 27 fev. 2017. 14 nov. 2013.
THUSWOHL, Maurício.

Lobby pró-transgênicos age no Congresso e na CTNBio. Carta Maior. Disponível em: < http:// cartamaior.com.br/?/Editoria/Meio-Ambiente/ Lobby-pro-transgenicos-age-no-Congresso-e-naCTNBio/3/12230>. Acesso em: 27 fev. 2017. 14 dez. 2006.

TRANSGÊNICOS...

Transgênicos são barrados na CTNBio.

Agronotícias. Disponível em: <http://

agronoticiasmt.com.br/noticias/transgenicossao-barrados-na-ctnbio.html>. Acesso em: 9 out. 2016. 27 nov. 2006.

WICKSON, Fern; WYNNE, Brian.

Ethics of science for policy in the environmental governance of biotechnology: MON810 Maize in Europe. Ethics, Policy and Environment, v.15, n.3, p.321-340. 2012.

WINNER, Langdon.

Do artifacts have politics? In: Mackenzie, Donald; Wajcman. Judy (Ed.). The social shaping of technology. Philadelphia: Open University Press. 1983.

\section{ZANONI, Magda.}

Transgênicos terapia genética células-tronco: questões para a ciência e para a sociedade Brasília: Nead; Instituto Interamericano de Cooperação para a Agricultura. 2004.

ZANONI, Magda; FERMENT, Gilles (Org.). Transgênicos para quem? Agricultura, ciência e sociedade. Brasília: Ministério do Desenvolvimento Agrário. 2011.

ZANONI, Magda et al.

O biorrisco e a Comissão Técnica Nacional de Biossegurança: lições de uma experiência. In: Zanoni, Magda; Ferment, Gilles (Org.). Transgênicos para quem? Agricultura, ciência e sociedade. Brasília: Ministério do Desenvolvimento Agrário. p.244-276. 2011. 